Review

\title{
Novel oral anticoagulants in non-valvular atrial fibrillation: Pharmacological properties, clinical trials, guideline recommendations, new antidote drugs and real-world data
}

\author{
Umut Kocabas $^{\mathrm{a}, *}$, Esra Kaya ${ }^{\mathrm{b}}$, Gökhan $\mathrm{Avcl}^{\mathrm{c}}$ \\ a Department of Cardiology, Soma State Hospital, Manisa, Turkey \\ b Department of Cardiology, Turgutlu State Hospital, Manisa, Turkey \\ c Department of Cardiology, Çanakkale State Hospital, Çanakkale, Turkey
}

\section{A R T I C L E I N F O}

\section{Article history:}

Received 11 July 2016

Received in revised form 28 August 2016

Accepted 29 August 2016

Available online 8 September 2016

\section{Keywords:}

Apixaban

Dabigatran

Direct thrombin inhibitors

Edoxaban

Factor Xa inhibitors

Rivaroxaban

\begin{abstract}
A B S T R A C T
Atrial fibrillation (AF) is the most common sustained cardiac arrhythmia. Ischemic stroke and systemic thromboembolism are the most fatal complications of AF. Vitamin K antagonists (VKA) are used in the prevention of AFrelated stroke and systemic thromboembolism. However, the use of VKAs is associated with limitations such as their narrow therapeutic index, the need for monitoring, and numerous food-drug interactions. Novel oral anticoagulants (NOACs) developed by researchers do not have those limitations and are better tolerated in patients with non-valvular atrial fibrillation. In this review, the pharmacological properties of NOACs, the results of NOAC clinical trials, the guideline recommendations, the important aspects of patient selection and clinical practice, new antidote drugs for NOACs and real-world data of NOACs in patients with non-valvular atrial fibrillation have been discussed.
\end{abstract}

(c) 2016 The Society of Cardiovascular Academy. Production and hosting by Elsevier B.V. This is an open access article under the CC BY-NC-ND license (http://creativecommons.org/licenses/by-nc-nd/4.0/).

\section{Contents}

Introduction

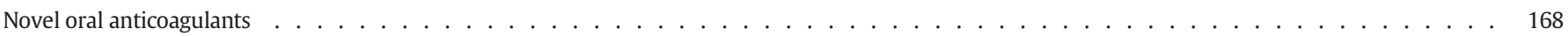

Dabigatran $\ldots \ldots . \ldots \ldots$

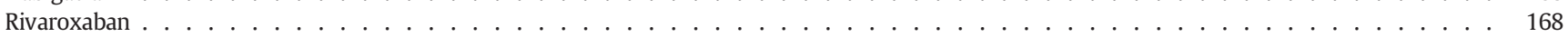

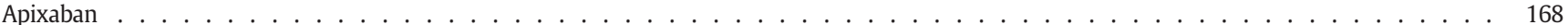

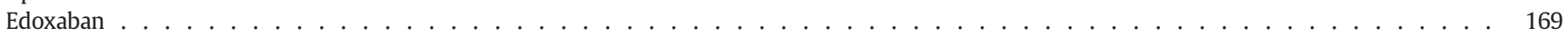

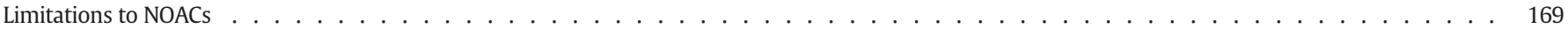

Novel oral anticoagulants in light of guidelines . . . . . . . . . . . . . . . . . . . . . . . . . . . . . . . . . . . . . 170

Monitoring novel oral anticoagulants . . . . . . . . . . . . . . . . . . . . . . . . . 170

Bleeding management . . . . . . . . . . . . . . . . . . . . . . . . . . . . . . . 170

Converting from anticoagulant treatment to NOACs and the perioperative approach . . . . . . . . . . . . . . . $\ldots$

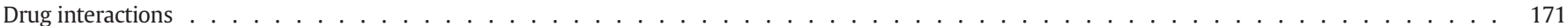

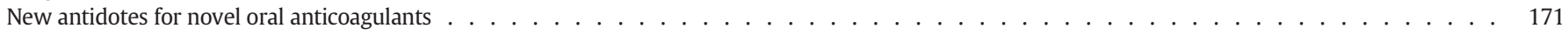

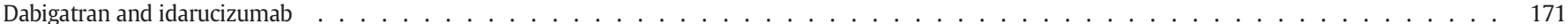

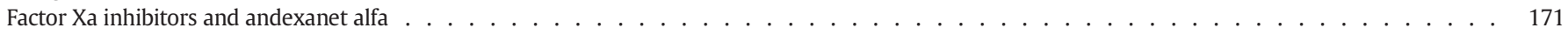

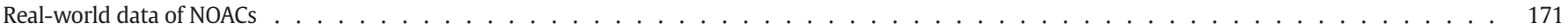

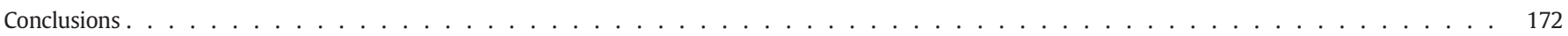

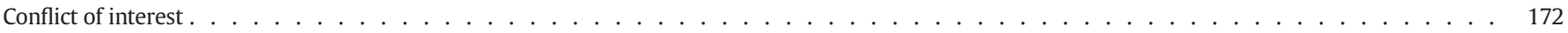

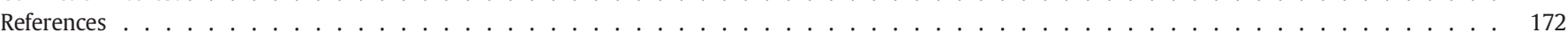

th Funding and support: Nothing to declare.

* Corresponding author at: Department of Cardiology, Soma State Hospital, Manisa 45500, Turkey.

E-mail address: umutkocabas@hotmail.com (U. Kocabas).

Peer review under responsibility of The Society of Cardiovascular Academy. 


\section{Introduction}

Atrial fibrillation (AF) is the most common sustained cardiac arrhythmia and is seen in $1-2 \%$ of the general population. ${ }^{1}$ The number of patients with AF in the United States was 2.2 million in 2010 and is expected to rise to 12 million by $2050 .^{2}$ Ischaemic stroke and systemic thromboembolism are the most severe and fatal complications of AF. $\mathrm{AF}$ is responsible for $15 \%$ of the ischaemic stroke cases among all age groups and this rate increases up to $30 \%$ in people older than 80 years. $^{3}$ Warfarin is a vitamin $\mathrm{K}$ antagonist (VKA) that has been used in the prevention of AF for over 50 years. Randomised trials have shown that warfarin is superior to placebo, aspirin and the combination of aspirin-clopidogrel in preventing stroke. ${ }^{4,5,6}$ Warfarin use is challenging due to its narrow therapeutic index and it has many food and drug interactions. Thus, only 50 to $60 \%$ of the patients with AF are prescribed warfarin therapy and in 30 to $50 \%$ of these patients the international normalised ratio (INR) levels cannot be maintained within the therapeutic index. ${ }^{7,8}$ Although the efficacy of warfarin and other VKAs has been proven, the low and suboptimal use has led to the development of novel oral anticoagulants (NOACs).

\section{Novel oral anticoagulants}

Vitamin $\mathrm{K}$ antagonists affect the vitamin $\mathrm{K}$ dependent factors II, VII, IX, and X of the coagulation cascade and novel oral anticoagulants (NOACs) affect specific steps. They are classified according to their effects as the direct thrombin inhibitors dabigatran and AZD0837, and the direct factor Xa inhibitors rivaroxaban, apixaban, edoxaban, betrixaban, LY-517,717 and ym-150 (Table 1). ${ }^{9}$ This review focuses on dabigatran, rivaroxaban, apixaban and edoxaban that are approved by the American Food and Drug Administration (FDA) for the prevention of stroke and systemic embolism in patients with non-valvular AF.

\section{Dabigatran}

Dabigatran etexilate is an oral pro-drug and is converted to its active form dabigatran, a reversible, direct and competitive thrombin inhibitor by serum esterases. ${ }^{10}$ Its half-life is $12-17 \mathrm{~h}$, and $80 \%$ of the drug is excreted renally. ${ }^{11}$ The RE-LY (Randomized Evaluation of Long-term Anticoagulation TherapY) trial, is a prospective, randomised controlled and open-labelled trial that compares the efficacy and safety of $110 \mathrm{mg}$ and $150 \mathrm{mg}$ doses of dabigatran to warfarin with respect to stroke and systemic embolisms. The trial was designed as a non-inferiority trial. 18,113 patients with mean $\mathrm{CHADS}_{2}$ scores of 2.1 were included in the trial and were randomised to receive dabigatran $(110 \mathrm{mg}$ or $150 \mathrm{mg}$, twice a day) or warfarin (INR 2-3). The primary endpoint was stroke or systemic embolism. With respect to the primary endpoint, the dose of $110 \mathrm{mg}$ dabigatran (1.53\% events/year) was non-inferior $(\mathrm{p}<0.001)$ to warfarin and the dose of $150 \mathrm{mg}$ dabigatran ( $1.1 \%$ events/year) was superior to warfarin $(p<0.001) .{ }^{12}$ The rate of major and life-threatening bleeding in the group of $150 \mathrm{mg}$ doses of dabigatran was similar to warfarin $(3.11 \%$ vs. $3.36 \%$ events/year respectively, $\mathrm{p}=0.31$ ) and the $110 \mathrm{mg}$ dose of dabigatran was associated with a $20 \%$ risk reduction ( $2.7 \%$ vs. $3.4 \%$ events/year, $\mathrm{p}=0.003$ ). When the major bleedings were evaluated independently according to their locations, the rate of intracranial haemorrhages was seen to be significantly lower in both of the dabigatran arms (110 mg BID and $150 \mathrm{mg}$ BID) than it was in the warfarin arm $(0.23 \%, 0.35 \%$ and $0.74 \%$ events/year respectively, $\mathrm{p}<0.001$ for both groups). On the other hand, it was seen that the $150 \mathrm{mg}$ dose of dabigatran increased the risk for gastrointestinal bleeding when compared to warfarin ( $1.51 \%$ and $1.02 \%$ respectively, $\mathrm{p}<0.001)$, and the $110 \mathrm{mg}$ dose of dabigatran was similar to warfarin $(1.12 \%$ and $1.02 \%$ respectively, $\mathrm{p}=0.43) .^{13}$

\section{Rivaroxaban}

Rivaroxaban is a direct factor Xa inhibitor. Its half-life is $5-9 \mathrm{~h}$ (9-13 $\mathrm{h}$ in the elderly) and $60-70 \%$ of the drug is excreted renally. ${ }^{11}$ The ROCKET-AF (Rivaroxaban Once daily oral direct factor Xa inhibition compared with vitamin $\mathrm{K}$ antagonism for prevention of stroke and Embolism Trial in Atrial Fibrillation) trial is a prospective, randomised, double-blind trial comparing rivaroxaban and warfarin in patients with non-valvular AF. Total of 14,264 patients with non-valvular AF with mean $\mathrm{CHADS}_{2}$ scores of 3.48 were included in the trial. Patients were randomised to receive $20 \mathrm{mg}$ /day doses of rivaroxaban ( $15 \mathrm{mg} /$ day if the creatinine clearance is $30-49 \mathrm{~mL} / \mathrm{min}$ ) or warfarin (target INR: 2-3). The primary end points were stroke and systemic embolism. When the trial was completed, it was shown that rivaroxaban was non-inferior to warfarin with respect to the primary endpoint ( $2.1 \%$ vs. $2.4 \%$ respectively, for non-inferiority $p<0.001$ ). There was no difference between the rates of major and clinically significant non-major bleeding rates between rivaroxaban and warfarin groups ( $14.9 \%$ vs. $14.5 \%$ events respectively, $\mathrm{p}=$ non-significant). In addition, the rate of intracranial haemorrhages was significantly lower in the rivaroxaban group $(0.5 \%$ and $0.7 \%$ events/year, $\mathrm{p}=0.02) .{ }^{14}$

\section{Apixaban}

Apixaban is an oral drug and is a direct competitive factor Xa inhibitor. It is absorbed rapidly, has a half-life of $10-14 \mathrm{~h}$ and $27 \%$ of the drug is excreted renally. ${ }^{15}$ The AVERROES trial (Apixaban Versus Acetylsalicylic Acid to Prevent Stroke in Atrial Fibrillation Patients Who Have Failed or Are Unsuitable for Vitamin K Antagonist Treatment) is a double-blind randomised trial including 5599 patients with AF for whom vitamin $\mathrm{K}$ antagonist therapy is inappropriate. The patients were randomised to receive apixaban ( $5 \mathrm{mg}$, twice a day) or aspirin (80-325 mg). The mean follow-up was 1.1 years. The rate of stroke or systemic embolism was $1.6 \%$ in the apixaban group and $3.7 \%$ in the aspirin group (HR $0.45,95 \% \mathrm{CI} 0.32-0.62, \mathrm{p}<0.001$ ). It was recommended to terminate the trial early because a significant benefit in favour of apixaban was demonstrated. There was no significant difference in major bleeding rates between apixaban and aspirin groups. In addition, it was shown that apixaban was tolerated better than aspirin as more cases in the aspirin group discontinued their treatment. ${ }^{16}$

Table 1

Comparison of pharmacokinetic profiles for the novel oral anticoagulants. ${ }^{12,14,15,20}$

\begin{tabular}{|c|c|c|c|c|}
\hline & Dabigatran & Rivaroxaban & Apixaban & Edoxaban \\
\hline Mechanism of action & Direct thrombin (factor IIa) inhibition & Direct factor Xa inhibition & Direct factor Xa inhibition & Direct factor Xa inhibition \\
\hline \multirow{2}{*}{ Dosing } & 110 mg oral, twice daily & 20 mg oral daily & 5 mg oral, twice daily & 60 mg oral daily \\
\hline & $150 \mathrm{mg}$ oral, twice daily & $\begin{array}{l}15 \mathrm{mg} \text { oral daily } \\
\text { (if } \mathrm{CrCl} 30-49 \mathrm{~mL} / \mathrm{min} \text { ) }\end{array}$ & $\begin{array}{l}2.5 \mathrm{mg} \text { oral, twice daily } \\
\text { (if creatinine }>133 \mathrm{mmol} / \mathrm{L} \text { ) }\end{array}$ & $30 \mathrm{mg}$ oral daily \\
\hline Elimination & $80 \%$ renal & $\sim 66 \%$ renal & $\sim 27 \%$ renal & $50 \%$ renal \\
\hline Pro-drug & Yes & No & No & No \\
\hline Half-life (h) & $12-17$ & $5-9$ (9-13 h in the elderly) & $10-14$ & $9-11$ \\
\hline $\operatorname{Tmax}(\mathrm{h})$ & 1 & $2-4$ & $3-4$ & $1-4$ \\
\hline
\end{tabular}

$\mathrm{CrCl}$ : creatinine clearance. 
Table 2

Comparison of data from major trials for the novel oral anticoagulants. ${ }^{12,14,15,20}$

\begin{tabular}{|c|c|c|c|c|}
\hline & RE-LY & ROCKET-AF & ARISTOTLE & ENGAGE AF-TIMI 48 \\
\hline Treatment arms & $\begin{array}{l}\text { Dabigatran ( } 110 \mathrm{mg} \text { or } 150 \mathrm{mg} \text {, } \\
\text { twice a day) vs. warfarin } \\
\text { (target INR: } 2-3 \text { ) }\end{array}$ & $\begin{array}{l}\text { Rivaroxaban } 20 \mathrm{mg} / \text { day }(15 \mathrm{mg} / \text { day } \\
\text { if the creatinine clearance is } \\
30-49 \mathrm{~mL} / \mathrm{min} \text { ) vs. warfarin (INR: } 2-3 \text { ) }\end{array}$ & $\begin{array}{l}\text { Apixaban ( } 5 \mathrm{mg} \text {, twice a day) vs. } \\
\text { warfarin (target INR: } 2-3 \text { ) }\end{array}$ & $\begin{array}{l}\text { Edoxaban }(30 \mathrm{mg} / \mathrm{d} \text { or } 60 \mathrm{mg} / \mathrm{d} \text { ) } \\
\text { vs. warfarin (target INR: } 2-3 \text { ) }\end{array}$ \\
\hline Trial design & Randomised, open-label & Randomised, double-blind & Randomised, double-blind & Randomised, double-blind \\
\hline Number of patients & 18.113 & 14.264 & 18.201 & 21.105 \\
\hline Mean age & 71.5 & 73 & 70 & 72 \\
\hline TTR of warfarin (\%) & 64 & 55 & 62 & 68 \\
\hline Mean $\mathrm{CHADS}_{2}$ score & 2.1 & 3.48 & 2.1 & 2.8 \\
\hline $\begin{array}{l}\text { Primary endpoint: stroke/ } \\
\text { systemic embolism } \\
\text { (\%/year) }\end{array}$ & $\begin{array}{l}1.53 \text { in } 110 \mathrm{mg} \text { dabigatran group, } \\
1.11 \text { in } 150 \mathrm{mg} \text { dabigatran group } \\
1.69 \text { in warfarin group } \\
\text { ( } p<0.001 \text { for non-inferiority for } \\
\text { both dabigatran groups) }\end{array}$ & $\begin{array}{l}2.1 \text { in rivaroxaban group and } 2.4 \text { in } \\
\text { warfarin group } \\
(p<0.001 \text { for non-inferiority })\end{array}$ & $\begin{array}{l}1.27 \text { in apixaban group and } 1.6 \\
\text { in warfarin group } \\
\text { ( } p<0.001 \text { for non-inferiority and } \\
p=0.01 \text { for superiority) }\end{array}$ & $\begin{array}{l}1.61 \text { in } 30 \text { mg edoxaban group, } \\
1.18 \text { in } 60 \text { mg edoxaban group } \\
\text { and } 1.50 \text { in warfarin group } \\
(p=0.005, p<0.001 \text { for } \\
\text { non-inferiority respectively) }\end{array}$ \\
\hline
\end{tabular}

INR: international normalised ratio; TTR: time-in-therapeutic range.

Another trial ARISTOTLE (Apixaban for Reduction in Stroke and Other Thromboembolic Events in Atrial Fibrillation) compared apixaban to warfarin. This trial was a double-blind, randomised, controlled noninferiority trial and included 18,201 patients with non-valvular AF with $\mathrm{CHADS}_{2}$ scores of 2.1 from 39 countries. The mean follow-up was 1.8 years. Patients were randomised to receive apixaban $(5 \mathrm{mg}$, twice a day) or warfarin. Patients who met two or more of the following criteria were administered half doses of apixaban: being over 80 years of age, weighing $60 \mathrm{~kg}$ and less or having serum creatinine levels higher than $1.5 \mathrm{mg} / \mathrm{dL}$. The primary composite endpoint, stroke or systemic embolism occurred in $212(1.27 \%)$ patients in the apixaban arm and $265(1.6 \%)$ patients in the warfarin arm ( $\mathrm{p}<0.001$ for non-inferiority, $\mathrm{p}=0.01$ for superiority).

According to the results, apixaban was superior to warfarin in preventing stroke and systemic embolisms in patients with nonvalvular AF. Apixaban was also superior to warfarin with respect to all-cause mortality rates (3.52\% vs. $3.94 \%, \mathrm{p}=0.047$ ). Regarding the safety endpoints, major bleeding occurred less in the apixaban arm $(2.13 \%)$ than the warfarin arm $(3.09 \%)(p<0.001)$. The rate of intracranial haemorrhages was $0.33 \%$ event/year in the apixaban group and $0.80 \%$ event/year in the warfarin group $(\mathrm{p}<0.001){ }^{15}$

\section{Edoxaban}

Edoxaban is a direct, specific and reversible inhibitor of factor Xa, delivered orally. Edoxaban has a half-life of approximately 9-11 h and its absolute oral bioavailability is $62 \%$. It quickly reaches peak plasma concentrations in $1.5 \mathrm{~h}$ and $50 \%$ of drug elimination is via the kidneys. ${ }^{17}$ The Effective Anticoagulation with Factor Xa Next Generation in Atrial Fibrillation-Thrombolysis in Myocardial Infarction 48 (ENGAGE AFTIMI 48) is a randomised, double-blind, multicentre trial comparing warfarin and edoxaban for thromboembolism and stroke prophylaxis in non-valvular atrial fibrillation. From 1393 hospitals in 46 countries, 21.105 subjects with a average $\mathrm{CHADS}_{2}$ score of 2.8 were randomized to edoxaban high dose (60 mg daily), edoxaban low dose (30 mg daily), or warfarin titrated to an international normalised ratio of 2.0 to 3.0. The primary compound endpoint was systemic embolism and stroke. Annual rate of the primary end point was $1.50 \%$ with warfarin (time-in-therapeutic range (TTR), 68\%), when compared to $1.18 \%$ with $60 \mathrm{mg}$ edoxaban ( $\mathrm{p}<0.001$ for non-inferiority) and $1.61 \%$ with $30 \mathrm{mg}$ edoxaban ( $\mathrm{p}=0.005$ for non-inferiority). Annual rate of major bleeding was $3.43 \%$ in warfarin, $2.75 \%$ and $1.61 \%$ for $60 \mathrm{mg}$ and $30 \mathrm{mg}$ edoxaban treatment respectively ( $p<0.001$ for both doses). Both doses of edoxaban were shown to be as efficient as warfarin for systemic embolism and stroke prophylaxis in non-valvular AF and were associated with significantly lower rates of bleeding and death from cardiovascular causes. On the other hand gastrointestinal bleeding rates were significantly higher in edoxaban $60 \mathrm{mg}$ group compared to warfarin therapy $(1.51 \%$ vs $1.23 \%$; $\mathrm{p}=0.03){ }^{18}$
We can summarise the four randomised controlled novel oral anticoagulant trials as follows:

1- In patients with non-valvular AF, novel oral anticoagulants are at least as effective as warfarin for the prevention of stroke and systemic embolism. ${ }^{12,14,15,18}$

2- When compared to warfarin, $150 \mathrm{mg}$ doses of dabigatran reduced the relative risk by $34 \%$ and apixaban reduced it by $21 \%$. Both of these drugs were superior to warfarin in preventing the primary endpoint. $^{12,15}$

3- The rates of intracranial haemorrhages and haemorrhagic stroke were significantly lower with novel oral anticoagulants. However, only $150 \mathrm{mg}$ doses of dabigatran were proven to be superior to warfarin in preventing ischemic stroke (relative risk reduction $24 \%)^{12,14,15,18}$

4- Only apixaban is superior to warfarin with respect to mortality of all causes $(p=0.047) .{ }^{15}$

5- With respect to other major bleedings except gastrointestinal bleeding, apixaban, $110 \mathrm{mg}$ doses of dabigatran and both doses of edoxaban are safer than warfarin (superior). Rivaroxaban and $150 \mathrm{mg}$ doses of dabigatran are at least as safe as warfarin (non-inferior). ${ }^{12,14,15,18}$

6- Rivaroxaban, $150 \mathrm{mg}$ doses of dabigatran and $60 \mathrm{mg}$ doses of edoxaban increase the risk of gastrointestinal bleeding when compared to warfarin. Apixaban, $110 \mathrm{mg}$ doses of dabigatran and $30 \mathrm{mg}$ doses of edoxaban are similar to warfarin (Table 2 ). ${ }^{12,14,15,18}$

\section{Limitations to NOACs}

The novel oral anticoagulant drugs have become popular in patients with non-valvular AF for the prevention of stroke and ischaemic embolisms because they do not require monitoring, they are easy to use and they cause fewer drug and food interactions. However, the different designs and inclusion criteria of the trials comparing NOACs, and the lack of trials comparing all three NOACs with each other raise controversy. The four large phase III trials (RE-LY, ROCKET-AF, ARISTOTLE and ENGAGE AF-TIMI 48) were all designed as non-inferiority trials. The RE-LY trial was an open-labelled trial but the ROCKET-AF, ARISTOTLE and ENGAGE AF-TIMI 48 trials were double-blind. ${ }^{12,14,15,18}$ In current guidelines, effective warfarin therapy is defined as an "INR level between 2.0 and 3.0 and the TTR as at least $70 \%$ of the entire treatment duration". ${ }^{1}$ The TTR in these trials differs significantly, the TTR is 55\% in the ROCKET-AF trial, $62 \%$ in the ARISTOTLE trial, $64 \%$ in the RE-LY trial and 68\% in the ENGAGE AF-TIMI 48 trial. Due to suboptimal time-in-therapeutic range the efficacy of warfarin could have been calculated lower than it should have been, thus, NOACs may have been determined as relatively non-inferior and/or superior to warfarin. ${ }^{19}$ Another important topic for discussion is the inclusion of patients from different risk groups for stroke. The mean $\mathrm{CHADS}_{2}$ scores in the 
RE-LY, ARISTOTLE, ENGAGE AF-TIMI 48 and ROCKET-AF trials were 2.1, $2.1,2.8$ and 3.5 respectively. This may be one of the reasons why rivaroxaban was not superior to warfarin with respect to the primary endpoints although apixaban and $150 \mathrm{mg}$ doses of dabigatran were superior. Another discussion topic is the association of dabigatran therapy with ischaemic myocardial events. This discussion was raised because the number of myocardial infarctions (MI) was higher in the dabigatran arm of the RE-LY trial than the warfarin arm. Due to this, MI, unstable angina, cardiac arrest and cardiac death rates on dabigatran treatment were analysed and published. The annual MI rates in the arms receiving $110 \mathrm{mg}$ or $150 \mathrm{mg}$ of dabigatran or apixaban were $0.82 \%, 0.81 \%$ and $0.64 \%$ respectively and there was no statistically significant difference. There was no significant difference between the rates of the primary composite endpoints unstable angina, MI, cardiac arrest and cardiac death either. ${ }^{20}$

\section{Novel oral anticoagulants in light of guidelines}

In the AF guideline and updates published by the European Society of Cardiology (ESC) in 2010 and 2012 it is stated that AF patients must undergo risk classification for stroke and the anticoagulant treatment requirements should be determined accordingly. For this purpose, instead of the CHADS 2 score it is recommended to use the $\mathrm{CHA}_{2} \mathrm{DS}_{2^{-}}$ VASc score that allows better differentiation of the "real low risk" cases. ${ }^{1}$ The ESC guideline does not recommend anticoagulant treatment for non-valvular AF patients in the real low-risk groups - i.e. patients under 65 years of age with no risk factors (with a $\mathrm{CHA}_{2} \mathrm{DS}_{2}$-VASc score of 0 ). Oral anticoagulants are offered as the single treatment option for cases with $\mathrm{CHA}_{2} \mathrm{DS}_{2}$-VASc scores $\geq 1$. Female patients are given 1 point for gender under any circumstance, however, they are not suitable candidates for anticoagulant therapy if they are under 65 years and have no risk factors. In other words, anticoagulant treatment is indicated for all patients with AF over the age of 65 . If the patient has a rheumatoid heart disease (especially mitral stenosis), a history of prosthetic valvular operations or mitral valve repair, and if the creatinine clearance is under $30 \mathrm{~mL} / \mathrm{min}$ the only suitable oral anticoagulant (OAC) is warfarin. In the rest of the patients with non-valvular AF, warfarin and all three NOACs are suitable for the same indications and have equivalent proof levels. ${ }^{21}$

The American College of Cardiology and the American Heart Association (ACC/AHA) have updated the guidelines they published in 2014 to recommend using the $\mathrm{CHA}_{2} \mathrm{DS}_{2}$-VASc score for risk classification instead of the $\mathrm{CHADS}_{2}$ score in a similar fashion to the ESC guidelines. ${ }^{22}$ The common aspects and differences between the guidelines important for clinical practice issued by the ESC and ACC/AHA can be summarised as follows:

* The ESC guidelines recommend OAC treatment for patients with $\mathrm{CHA}_{2} \mathrm{DS}_{2}$-VASc scores of 1 , the ACC/AHA guidelines state that treatment may not be necessary, OAC treatment can be administered or treatment with aspirin may be considered. ${ }^{21,22}$

* In patients with $\mathrm{CHA}_{2} \mathrm{DS}_{2}$-VASc scores of 0 both guidelines state that treatment is not required. ${ }^{21,22}$

* The ESC guidelines do not recommend using NOACs in patients who have renal failure with $\mathrm{CrCl}$ (creatinine clearance) $<30 \mathrm{~mL} / \mathrm{min}$, the ACC/AHA guidelines state that NOACs should not be used in endstage chronic renal failure patients $(\mathrm{CrCl}<15 \mathrm{~mL} / \mathrm{min})$ or in cases in haemodialysis programs and that warfarin is the drug of choice for these patients. ${ }^{21,22}$

* The ESC guidelines recommend using a $110 \mathrm{mg}$ dose of dabigatran twice a day for patients with renal failure and $\mathrm{CrCl}=$ $30-49 \mathrm{~mL} / \mathrm{min}$. The ACC/AHA guidelines state that $150 \mathrm{mg}$ or $75 \mathrm{mg}$ BID doses of dabigatran can be used in this patient group. ${ }^{21,22}$

* The ACC/AHA guidelines state that $75 \mathrm{mg}$ doses of dabigatran twice a day or $15 \mathrm{mg} /$ day doses of rivaroxaban can be used in renal failure patients with $\mathrm{CrCl}=15-30 \mathrm{~mL} / \mathrm{min}$. However, it is stated that this recommendation is not based on data from prospective studies. ${ }^{22}$

\section{Monitoring novel oral anticoagulants}

Unlike warfarin, the novel oral anticoagulants do not require routine monitoring. It may be necessary to assess the efficacy of NOACs in some specific clinical situations such as bleeding, newly developed or deteriorating renal failure, stroke or systemic embolism. ${ }^{23}$ However, there is no specific coagulation test that can be used to determine the efficacy of the NOAC drugs in these clinical conditions. The most useful approach used for this purpose is measuring the thrombin or ecarin clotting times. Especially during emergencies, the activated partial thromboplastin time is another measure that can be used during dabigatran treatment. However, it must not be forgotten that high blood levels of the drugs may lead to erroneous activated partial thromboplastin time readings. ${ }^{24}$ The coagulation test used for rivaroxaban patients is the prothrombin test. ${ }^{25}$ The factor Xa levels can also be used to monitor rivaroxaban, apixaban and edoxaban. ${ }^{25,26}$

\section{Bleeding management}

There are a few novel antidotes used to antagonise drug effects in bleedings induced by NOACs. Treatment with plasma is ineffective because the bleeding is not due to factor deficiency; thrombin and factor Xa inhibitors are already present in the patient's blood. It is thought that cryoprecipitate may be useful in dabigatran-induced bleedings and that prothrombin concentrates may be useful in apixaban or rivaroxaban-induced bleedings. The only emergency approach proven to be useful in the treatment of dabigatran-induced bleeding is the use of activated charcoal followed by haemodialysis to remove the drug from the body. ${ }^{27}$ Currently, there is a few new specific antidote drugs to treat major bleedings associated with new generation oral anticoagulants. Thus, the most important point that needs to be considered by the physician is the selection of the most suitable drug and dose regimen.

\section{Converting from anticoagulant treatment to NOACs and the perioperative approach}

The use of novel oral anticoagulants is increasing as they have advantages over warfarin. Their onset of effect is rapid, they do not cause significant food and drug interactions and they do not require monitoring. If a patient on NOAC therapy is going to have surgery the most important question is when to stop the drug before the surgery. The definitive issue is the functional capacity of the patient's kidneys. According to current consensus reports it is recommended to assess the creatinine clearance at least seven days before the surgery before making a decision. Important aspects to consider when deciding when to stop NOAC therapy before surgery are given in Table 3.

When converting from warfarin to one of the novel oral anticoagulants, the novel oral anticoagulant must be started when the INR is below 2, in the opposite case double-treatment must be continued until INR reaches efficient levels. When converting from low molecular weight heparin (LMWH) to new generation oral anticoagulants heparin must be discontinued after delivering the final dose, and the new generation oral anticoagulant must be started $2 \mathrm{~h}$ before the time of the next dose of heparin that was to have been administered. In the opposite case, the first dose of heparin must be delivered 12 or $24 \mathrm{~h}$ after the last dose of the novel oral anticoagulant. ${ }^{27}$ When it is desired to convert to NOACs from infusions of unfractionated heparin the first NOAC dose should be administered at the time of the discontinuation of the infusion.

In the postoperative period it is recommended to restart the NOAC therapy as soon as possible once haemostasis is maintained. Intravenous heparin or LMWH bridge treatment is not required in the postoperative period as the effects of NOACs end rapidly and once restarted they rapidly reach therapeutic efficacy within $2 \mathrm{~h}^{28}$ 
Table 3

Preoperative interruption of novel oral anticoagulants. ${ }^{45,46,47}$

\begin{tabular}{|c|c|c|c|}
\hline Drug & Renal function & $\begin{array}{l}\text { Low bleeding risk surgery } \\
\text { (last dose) }\end{array}$ & $\begin{array}{l}\text { High bleeding risk surgery } \\
\text { (last dose) }\end{array}$ \\
\hline \multirow[t]{2}{*}{$\begin{array}{l}\text { Dabigatran } \\
\text { (150 mg twice daily) }\end{array}$} & $\begin{array}{l}\text { Normal or mild impairment } \\
(\mathrm{CrCl} \geq 50 \mathrm{~mL} / \mathrm{min})\end{array}$ & $24 \mathrm{~h}$ before surgery & $48-72 \mathrm{~h}$ before surgery \\
\hline & $\begin{array}{l}\text { Moderate impairment } \\
(\mathrm{CrCl} 30-49 \mathrm{~mL} / \mathrm{min})\end{array}$ & $48-72 \mathrm{~h}$ before surgery & $96 \mathrm{~h}$ before surgery \\
\hline \multirow[t]{2}{*}{$\begin{array}{l}\text { Rivaroxaban } \\
\text { ( } 20 \text { mg once daily) }\end{array}$} & $\begin{array}{l}\text { Normal or mild impairment } \\
(\mathrm{CrCl} \geq 50 \mathrm{~mL} / \mathrm{min})\end{array}$ & $24 \mathrm{~h}$ before surgery & $48-72 \mathrm{~h}$ before surgery \\
\hline & $\begin{array}{l}\text { Moderate impairment } \\
(\mathrm{CrCl} 30-49 \mathrm{~mL} / \mathrm{min})\end{array}$ & $48 \mathrm{~h}$ before surgery & $72 \mathrm{~h}$ before surgery \\
\hline \multirow[t]{2}{*}{$\begin{array}{l}\text { Apixaban } \\
\text { (5 mg twice daily) }\end{array}$} & $\begin{array}{l}\text { Normal or mild impairment } \\
(\mathrm{CrCl} \geq 50 \mathrm{~mL} / \mathrm{min})\end{array}$ & $24 \mathrm{~h}$ before surgery & $48-72 \mathrm{~h}$ before surgery \\
\hline & $\begin{array}{l}\text { Moderate impairment } \\
(\mathrm{CrCl} 30-49 \mathrm{~mL} / \mathrm{min})\end{array}$ & $48 \mathrm{~h}$ before surgery & $72 \mathrm{~h}$ before surgery \\
\hline
\end{tabular}

$\mathrm{CrCl}$ : creatinine clearance.

\section{Drug interactions}

The drug interactions of NOACs are another important issue. Although NOACs cause less drug interactions than warfarin, the drug interactions of NOACs must be known and a detailed pharmaceutical history of the patient must be obtained before prescribing these drugs.

Dabigatran requires an acidic medium for absorption because it contains tartaric acid. While antacids and $\mathrm{H} 2$ receptor antagonists do not affect the absorption of dabigatran; pantoprazole, a proton-pump inhibitor prevents the formation of an acidic medium and reduces the absorption of dabigatran. $^{29}$

The inhibition and induction of P-glycoprotein (P-gp) play an important role in the metabolism of dabigatran and also affect its blood levels. In patients using drugs like amiodarone, verapamil, quinidine, ketoconazole that inhibit P-gp, dabigatran must be avoided or used with caution at low doses. On the other hand, it must not be forgotten that concomitant use of the P-gp inducer rifampicin may reduce the therapeutic efficacy of dabigatran. In patients using ketoconazole, clarithromycin, ritonavir and other protease inhibitors that inhibit CYP3A4, apixaban and rivaroxaban must be used with caution because the blood levels and efficacy of the drugs may increase. ${ }^{29}$

\section{New antidotes for novel oral anticoagulants}

Life-threatening bleeding is the most important complication of NOACs. Lack of antidotes for NOACs is another crucial point when urgent intervention or surgery is needed. ${ }^{30}$ That brings the necessity of a fast-affecting and specific antidote for reversal of anticoagulation. Clinical trials in progress are evaluating the efficacy and safety of idarucizumab and andexanet alpha. ${ }^{31}$

\section{Dabigatran and idarucizumab}

Idarucizumab (aDabi-Fab, BI 655075) which is a human monoclonal antibody is the first specific dabigatran antidote. Binding specifically to dabigatran, idarucizumab antagonises its effects. Compared to thrombin it has a 350 -fold increased affinity to dabigatran. ${ }^{32}$ "The Study of the REVERSal Effects of Idarucizumab in Patients on Active Dabigatran (RE-VERSE AD)' is a phase 3 trial investigating the efficacy and safety of idarucizumab in patients with life-threatening bleeding and/or patients require urgent surgery or intervention. ${ }^{33}$ In this prospective cohort study, anticoagulation reversal capacity of $5 \mathrm{mg}$ of idarucizumab is evaluated by measuring diluted thrombin time (dTT) and ecarin clotting time (ECT) before and $4 \mathrm{~h}$ after administration of idarucizumab. According to the pre-analysis results of the study, in patients with an increased coagulation profile (elevated dTT in 68; elevated ECT in 81 patients) median maximum reversal rate was $100 \%{ }^{34}$

\section{Factor Xa inhibitors and andexanet alfa}

Andexanet alfa (PRT064445, r-Antidote; Portola Pharmaceuticals) is an enzymatically inactive modified recombinant human factor Xa decoy protein which has an increased affinity to factor Xa inhibitors (rivaroxaban, apixaban and edoxaban) and antagonises the anticoagulant effects. ${ }^{35}$ Andexanet Alfa, a Novel Antidote to the Anticoagulation Effects of FXA Inhibitors Apixaban (ANNEXA-A) and Rivaroxaban (ANNEXA-R) trials are designed to evaluate the efficacy and safety of andexanet alfa, which is used to antagonise the anticoagulant effects of apixaban and rivaroxaban in healthy volunteers. In this randomised, placebo controlled, double-blind trial 101 participants between ages $50-75$ years ( 48 patients in apixaban and 53 patients in rivaroxaban arm) were randomised to either andexanet alfa or placebo. In andexanet alfa arm, following the administration of the antidote, the activity of anti-factor Xa decreased rapidly and significantly within minutes (2-5 min) compared to placebo (andexanet alfa vs. placebo, decreasing of anti-faactor Xa for apixaban [mean \pm SD] $94 \pm 2 \%$ vs. $21 \pm 9 \%$; p < 0.001, for rivaroxaban için $92 \pm 11 \%$ vs $18 \pm 15 \%$; $\mathrm{p}<0.001)^{36}$

\section{Real-world data of NOACs}

Current guidelines recommend NOAC drugs for prevention of stroke in non-valvular AF patients. Recommendations and level of evidences of the guidelines are based on randomised trials of NOACs. Nevertheless, as some patient groups which are common in routine daily practice are not included in those trials, real-world data investigating the safety and efficacy of NOACs is needed. Designed for that purpose, XANTUS trial is an international, large-scaled, prospective, observational study collecting the real-world data of rivaroxaban which is used in stroke prevention in non-valvular AF patients. A total of 6784 patients (mean age: 71.5 years, $59 \%$ male) who were treated with rivaroxaban for non-valvular AF were included in the study and were followed up for one year independent of the risk of stroke. Mean $\mathrm{CHADS}_{2}$ score was 2.0. Mild to severe renal insufficiency $(\mathrm{CrCl}<50 \mathrm{~mL} / \mathrm{min})$ was seen in $9.4 \%$ of patients. In safety results of the trial, fatal bleeding ( 0.2 events per $100 \mathrm{p} / \mathrm{y}$ ) in $0.2 \%$ of patients and major bleeding ( $\mathrm{n}=128$, 2.1 events per $100 \mathrm{p} / \mathrm{y}$ ) in $1.9 \%$ of patients occurred. Symptomatic thromboembolism (stroke, transient ischaemic attack, systemic embolism, MI) was seen in $1.6 \%$ of patients (n:108). In comparison with ROCKET-AF trial, mean CHADS 2 score (3.5 for ROCKET-AF and 2.0 for XANTUS), all-cause mortality rates, major bleeding, stroke and MI rates were lower in XANTUS trial. ${ }^{37}$

United States Department of Defence Post-marketing Safety Surveillance (PMSS) trial is a retrospective, observational study designed to identify the major bleeding incidence associated with rivaroxaban. A total of 39.052 patients who were treated with rivaroxaban for total hip/knee surgery or non-valvular AF were included in the study. 
Rivaroxaban associated major bleeding incidence was 2.89 events per 100 person-years $(\mathrm{n}=970)$. Most of the major bleedings were gastrointestinal bleedings ( 846 patients, $87.2 \%$ ). Fatal bleeding incidence was $0.1 \%(n=35)$. Intracranial haemorrhages were responsible for $74.3 \%$ of fatal bleeding. ${ }^{38}$ Results of the study were consistent with ROCKET-AF trial. The results of XANTUS and PMSS trials analysing the real-world data confirmed the results of ROCKET-AF trial. ${ }^{39}$

Effectiveness and Safety of Dabigatran and Warfarin in Real-world US Patients With Non-Valvular Atrial Fibrillation: A Retrospective Cohort Study is a retrospective, observational study, conducted between 2010 and 2012, including patients with non-valvular AF on vitamin K antagonists or dabigatran therapy. A total of 64.935 patients were included in the study of whom $32.5 \%$ were on dabigatran therapy. Compared to warfarin, dabigatran was associated with lower risks of ischaemic stroke or systemic embolism (composite adjusted HR: 0.86, 95\% CI: 0.79 to 0.93 ), haemorrhagic stroke (HR: $0.51,95 \% \mathrm{CI}: 0.40$ to 0.65 ) and MI (HR: $0.88,95 \% \mathrm{CI}: 0.77$ to 0.99$)$. Conversely dabigatran was associated with increased risk of GI bleeding (HR: 1.11, 95\% CI: 1.02 to 1.22$).{ }^{40}$ Supportively, Graham et al. conducted a study with real-world data to find that $150 \mathrm{mg}$ dabigatran was associated with lesser death, ischaemic stroke, intracranial haemorrhage risks and therefore increased GI bleeding risk. ${ }^{41}$ On the contrary, in a trial by Hernandez et al. Dabigatran was associated with increased risks of bleeding (HR: 1.30, 95\% CI: 1.20-1.41), major bleeding (HR: 1.58, 95\% CI: 1.36-1.83) and GI bleeding (HR: 1.85, 95\% CI: 1.64-2.07). Intracranial haemorrhage was significantly lesser in dabigatran arm, similar to RE-LY trial. Investigators emphasize that bleeding risk was higher especially in patients with co-dominant comorbidities and that dabigatran should be used with caution in those patients. ${ }^{42}$ In a recent report published by FDA which was based on real-world data, dabigatran was associated with lower risks of stroke, death and intracranial haemorrhage. ${ }^{43}$ In a trial which was conducted between 2007 and 2010 and was evaluating real-world data of non-valvular AF patients, NOACs were associated with lower rates of stroke compared to warfarin. It was emphasised that when excluding intracranial haemorrhages, apixaban was the only NOAC decreasing major bleeding rates. Numbers needed to treat (NNT) values for net clinical benefit (stroke plus major bleeding except intracranial haemorrhage) were 32 and 84 for apixaban and dabigatran respectively. ${ }^{44}$

\section{Conclusions}

The novel oral anticoagulant drugs for prevention of stroke in nonvalvular AF have been evolved and adding new options and advantages for patients and physicians such as fewer frequency of drug and food interactions, no need for monitoring, broad therapeutic index and tolerated better by patients.

Large-scale phase III trials are completed for dabigatran, rivaroxaban, apixaban, edoxaban and all these trials ended up with non-inferiority of these new anticoagulant drugs compared with warfarin for prevention of stroke for patients with non-valvular atrial fibrillation. Additionally, compared with VKA, dabigatran $150 \mathrm{mg}$ and apixaban twice daily were superior and associated with significant reductions in the incidence of stroke. Intracranial haemorrhages and haemorrhagic stroke occurred significantly less with novel oral anticoagulants. Especially in patients with poorly controlled INR values in follow-up, the potential advantages of the NOACS are likely to be most manifest.

\section{Conflict of interest}

We have no commercial, financial, and other relationships in any way related to the subject of this article that might create any potential conflict of interest.

\section{References}

1. Camm AJ, Kirchhof P, Lip GY, et al. Guidelines for the management of atrial fibrillation: the Task Force for the Management of Atrial Fibrillation of the European Society of Cardiology (ESC). Eur Heart J 2010;31:2369-2429.

2. Singer DE, Albers GW, Dalen JE, et al. Antithrombotic therapy in atrial fibrillation: American College of Chest Physicians Evidence-based Clinical Practice Guidelines. Chest 2008;133:546-592.

3. Wolf PA, Abbott RD, Kannel WB. Atrial fibrillation: a major contributor to stroke in the elderly. The Framingham Study. Arch Intern Med 1987;147:1561-1564.

4. Hart RG, Benavente O, McBride R, et al. Antithrombotic therapy to prevent stroke in patients with atrial fibrillation: a meta-analysis. Ann Intern Med 1999:131:492-501.

5. Mant J, Hobbs FD, Fletcher K, et al. Warfarin versus aspirin for stroke prevention in an elderly community population with atrial fibrillation (the Birmingham Atrial Fibrillation Treatment of the Aged Study, BAFTA): a randomised controlled trial. Lancet 2007:370:493-503.

6. ACTIVE Writing Group of the ACTIVE Investigators, Connolly S, Pogue J, et al. Clopidogrel plus aspirin versus oral anticoagulation for atrial fibrillation in the atrial fibrillation clopidogrel trial with Irbesartan for prevention of vascular events (ACTIVE W): a randomised controlled trial. Lancet 2006;367:1903-1912.

7. Connolly SJ, Eikelboom J, O'Donnell M, et al. Challenges of establishing new antithrombotic therapies in atrial fibrillation. Circulation 2007;116:449-455.

8. van Walraven $C$, Jennings $A$, Oake $N$, et al. Effect of study setting on anticoagulation control: a systematic review and metaregression. Chest 2006;129:1155-1166.

9. Eriksson BI, Quinlan DJ, Weitz JI. Comparative pharmacodynamics and pharmacokinetics of oral direct thrombin and factor Xa inhibitors in development. Clin Pharmacokinet 2009;48:1-22.

10. Connolly SJ, EzekowitzMD YS, et al. Dabigatran versus warfarin in patients with atrial fibrillation. N Engl J Med 2009;361:1139-1151.

11. Cabral KP, Ansell J, Hylek EM. Future directions of stroke prevention in atrial fibrillation: the potential impact of novel anticoagulants and stroke risk stratification. J Thromb Haemost 2011;9:441-449.

12. Ezekowitz MD, Connolly S, Parekh A, et al. Rationale and design of RE-LY: randomized evaluation of long-term anticoagulant therapy, warfarin, compared with dabigatran. Am Heart J 2009;157:805-810.

13. Eikelboom JW, Wallentin L, Connolly SJ, et al. Risk of bleeding with 2 doses of dabigatran compared with warfarin in older and younger patients with atrial fibrillation: an analysis of the randomized evaluation of long-term anticoagulant therapy (RE-LY) trial. Circulation 2011;123:2363-2372.

14. ROCKET AF Study Investigators. Rivaroxaban-once daily, oral, direct factor Xa inhibition compared with vitamin $\mathrm{K}$ antagonism for prevention of stroke and embolism trial in atrial fibrillation: rationale and design of the ROCKET AF study. Am Heart J 2010;159:340-347.

15. Lopes RD, Alexander JH, Al-Khatib SM, et al. Apixaban for reduction in stroke and other thromboembolic events in atrial fibrillation (ARISTOTLE) trial: design and rationale. Am Heart J 2010;159:331-339.

16. Eikelboom JW, O'Donnell M, Yusuf S, et al. Rationale and design of AVERROES: apixaban versus acetylsalicylic acid to prevent stroke in atrial fibrillation patients who have failed or are unsuitable for vitamin $\mathrm{K}$ antagonist treatment. Am Heart J 2010;159:348-353.

17. Ogata K, Mendell-Harary J, Tachibana M, et al. Clinical safety, tolerability, pharmacokinetics, and pharmacodynamics of the novel factor Xa inhibitor edoxaban in healthy volunteers. J Clin Pharmacol 2010;50:743-753.

18. Ruff CT, Giugliano RP, Antman EM, et al. Evaluation of the novel factor Xa inhibitor edoxaban compared with warfarin in patients with atrial fibrillation: design and rationale for the effective anticoagulation with factor xA next GEneration in atrial fibrillation-thrombolysis in myocardial infarction study 48 (ENGAGE AF-TIMI 48) Am Heart J 2010;160:635-641.

19. Xu B, Whitbourn R. Novel anticoagulants for non-valvular atrial fibrillation. Heart Lung Circ 2012;21:463-467.

20. Hohnloser SH, Oldgren J, Yang S, et al. Myocardial ischemic events in patients with atrial fibrillation treated with dabigatran or warfarin in the RE-LY (randomized evaluation of long-term anticoagulation therapy) trial. Circulation 2012;125: 669-676.

21. Camm AJ, Lip GY, De Caterina R, et al. 2012 focused update of the ESC guidelines for the management of atrial fibrillation: an update of the 2010 ESC guidelines for the management of atrial fibrillation. Developed with the special contribution of the European Heart Rhythm Association. Eur Heart J 2012;33:2719-2747.

22. January CT, Wann LS, Alpert JS, et al. 2014 AHA/ACC/HRS guideline for the management of patients with atrial fibrillation: executive summary: a report of the American College of Cardiology/American Heart Association Task Force on practice guidelines and the Heart Rhythm Society. Circulation 2014;130:2071-2104.

23. Tran H, Joseph J, Young L, et al. New oral anticoagulants: a practical guide on prescription, laboratory testing and peri-procedural/bleeding management. Australasian Society of Thrombosis and Haemostasis. Intern Med J 2014;44:525-536.

24. van Ryn J, Stangier J, Haertter S, et al. Dabigatran etexilate-a novel, reversible, oral direct thrombin inhibitor: interpretation of coagulation assays and reversal of anticoagulant activity. Thromb Haemost 2010;103:1116-1127.

25. Harenberg J, Krämer S, Du S, et al. Measurement of rivaroxaban and apixaban in serum samples of patients. Eur J Clin Investig 2014;44:743-752.

26. Douxfils J, Chatelain C, Chatelain B, et al. Impact of apixaban on routine and specific coagulation assays: a practical laboratory guide. Thromb Haemost 2013;110:283-294.

27. Douketis JD, Spyropoulos AC, Spencer FA, et al. Perioperative management of antithrombotic therapy: antithrombotic therapy and prevention of thrombosis, 9th ed: American College of Chest Physicians Evidence-based Clinical Practice Guidelines. Chest 2012;141:326-350. 
28. Hankey GJ. Anticoagulant therapy for patients with ischaemic stroke. Nat Rev Neurol 2012;8:319-328.

29. Walenga JM, Adiguzel C. Drug and dietary interactions of the new and emerging oral anticoagulants. Int J Clin Pract 2010;64:956-967.

30. Das A, Liu D. Novel antidotes for target specific oral anticoagulants. Exp Hematol Oncol 2015;4:25.

31. Bauer KA. Targeted anti-anticoagulants. N Engl J Med 2015;373:569-571.

32. Schiele F, van Ryn J, Canada K, et al. A specific antidote for dabigatran: functional and structural characterization. Blood 2013;121:3554-3562.

33. Pollack Jr CV, Reilly PA, Bernstein R, et al. Design and rationale for RE-VERSE AD: a phase 3 study of idarucizumab, a specific reversal agent for dabigatran. Thromb Haemost 2015;114:198-205.

34. Pollack Jr CV, Reilly PA, Eikelboom J, et al. Idarucizumab for dabigatran reversal. $N$ Engl J Med 2015;373:511-520.

35. Gomez-Outes A, Suarez-Gea ML, Lecumberri R, et al. Specific antidotes in development for reversal of novel anticoagulants: a review. Recent Pat Cardiovasc Drug Discov 2014;9:2-10.

36. Siegal DM, Curnutte JT, Connolly SJ, et al. Andexanet alfa for the reversal of factor Xa inhibitor activity. N Engl J Med 2015;373:2413-2424.

37. Camm AJ, Amarenco P, Haas S, et al. XANTUS: a real-world, prospective, observational study of patients treated with rivaroxaban for stroke prevention in atrial fibrillation. Eur Heart J 2016;37:1145-1153.

38. Tamayo S, Patel M, Yuan Z, et al. Post-marketing pharmacovigilance study for the active detection and evaluation of majör bleeding in rivaroxaban users with nonvalvular atrial fibrillation. J Am Coll Cardiol 2015;65:10.

39. Camm J. International, large-scale, real-world clinical data confirm the safety profile of rivaroxaban. EMJ Cardiol 2015;3:82-88.
40. Lauffenburger JC, Farley JF, Gehi AK, et al. Effectiveness and safety of dabigatran and warfarin in real-world US patients with non-valvular atrial fibrillation: a retrospective cohort study. J Am Heart Assoc 2015;4 [pii: e001798].

41. Graham DJ, Reichman ME, Wernecke M, et al. Cardiovascular, bleeding, and mortality risks in elderly Medicare patients treated with dabigatran or warfarin for nonvalvular atrial fibrillation. Circulation 2015;131:157-164.

42. Hernandez I, Baik SH, Piñera A, et al. Risk of bleeding with dabigatran in atrial fibrillation. JAMA Intern Med 2015;175:18-24.

43. Drug Safety Communication FDA. FDA study of Medicare patients finds risks lower for stroke and death but higher for gastrointestinal bleeding with Pradaxa (dabigatran) compared to warfarin. [Available at:] http://www.fda.gov/Drugs/ DrugSafety/ucm396470.htm.

44. Amin A, Stokes M, Wu N, et al. Abstract 261: applying clinical trial data to real-world: apixaban, dabigatran, and rivaroxaban. [Available at:] http://circoutcomes. ahajournals.org/content/7/Suppl_1/A261.abstract.

45. Kubitza D, Becka M, Wensing G, et al. Safety, pharmacodynamics, and pharmacokinetics of BAY 59-7939 - an oral, direct factor Xa inhibitor - after multiple dosing in healthy male subjects. Eur J Clin Pharmacol 2005;61:873-880.

46. Levy JH, Faraoni D, Spring JL, et al. Managing new oral anticoagulants in the perioperative and intensive care unit setting. Anesthesiology 2013;118:1466-1474.

47. Spyropoulos AC, Douketis JD, Gerotziafas G, et al. Periprocedural antithrombotic and bridging therapy: recommendations for standardized reporting in patients with arterial indications for chronic oral anticoagulant therapy. J Thromb Haemost 2012;10: 692-694 